\title{
For Smooth Study Connection of Fundamental Mathematical Sciences in a Joint Degree Program between Japan and Malaysia
}

\author{
Sengoku Yu \\ University Kuala Lumpur, Malaysia
}

\begin{abstract}
Smooth study connection between original and foreign universities or organizations is important for international students who belong to joint degree programs to study well in wholly new environment. In the case of a joint degree program between Japan and Malaysia, the subjects of fundamental mathematical sciences can be obstacles on smooth study connection because Malaysian university students are not necessarily good at ones taught in higher education. First I considered the reason why they were not good at fundamental mathematical sciences. Then I counted how many centers and departments in universities in Japan provided the classes of "Science and Technology Japanese" and / or "Basic Mathematics", which may be useful for them to overcome fundamental mathematical sciences. It turned out that few sections in universities in Japan provided such classes. Finally I propose that universities in Japan should provide more chances for international students to study such classes, that they should be careful of transferring credits of the classes of fundamental mathematical sciences, and that lecturers in both universities should share information about the contents of the subjects taught in both countries and share the scores of the students.
\end{abstract}

\section{Introduction}

Today joint degree programs are more popular than ever before. For example, joint degree programs have been the focus of attention in the framework of Bologna Process in Europa [1]. It is true in Japan because Japanese government announced "300000 Foreign Students Plan" and many Japanese universities have been eager to accept international students [2]. Joint degree programs are divided into four models by how many institutions participate and how many programs are offered [3]. In the interinstitutional and intra-program joint degree program classified by Michael and Balraj, students study in some universities or organizations under one program. They study in universities or organizations overseas after they do in their home countries if they are international students. It is thus desirable that they begin to study at new classes in foreign universities or organizations without feeling as much difficulty as possible. In this context, it is important for them to connect their studies smoothly between their original universities or organizations and new ones because it is likely that starting studies smoothly has any effect on whether their studies are successful and they can obtain degrees or not in foreign universities or organizations.

In this paper I focus on the case of a joint degree program between Japan and Malaysia, which I belong to as a lecturer. After confirming the subjects of fundamental mathematical sciences can be obstacles for smooth study connection for Malaysian university students, a survey is conducted on why they felt difficulty in studying fundamental mathematical sciences from their answer sheets. I report how many classes are provided in universities in Japan to solve such problems in the next section. Finally measures universities in Japan should take are proposed for international students to start to study well in Japan.

\section{Background of the Problem}

Japan and Malaysia have been in good relation in many fields, especially in the field of education. Malaysia has been sending many international students to Japan along "Look East Policy", proposed in 1982 by former Prime Minister Mahathir bin Mohamad. Malaysia is the $8^{\text {th }}$ country in the number of the students who study in Japan and is one of the significant countries which provide international students to Japan [4]. There are three major joint degree programs between Japan and Malaysia, which are AAJ (Ambang Asuhan Jepun), KTJ (Kumpulan Teknikal Jepun) and MJHEP (Malaysia Japan Higher Education Program). In these programs students spend their preparation years for higher education or for upper secondary education and occasionally spend university first and second years in institutions in Malaysia and then they study in universities or organizations in Japan. In MJHEP, which I belong to as a mathematics and 
informatics lecturer, students spend one year as matriculation students, which means students in preparation year for university entrance, and spend two years as university students in Malaysia and then they study for two years as junior and senior at universities in Japan.

Though students who won the highest scores in SPM (Sijil Pelajaran Malaysia, Malaysian certificate of secondary education) are permitted to study at MJHEP and go to Japan to study, they are not necessarily good at the subjects of fundamental mathematical sciences in Japan. Here I regard calculus, linear algebra and so on as the subjects of fundamental mathematical sciences. JUCTe (Japanese University Consortium for Transnationaleducation) reported that about $41.61 \%$ of the Malaysian university students got "C" or dismissed the subjects of fundamental sciences including fundamental mathematical sciences in Japan though only about $22.09 \%$ of them got "C" or dismissed the specialized subjects, about $22.29 \%$ the subjects of liberal arts and about $14.42 \%$ the subjects of languages [5]. The percentage of the subjects of fundamental mathematical sciences to the " $\mathrm{C}$ " or dismissed subjects of fundamental sciences was the highest $(33.43 \%)$ compared with those of fundamental physics, chemistry, informatics and so on. The subjects of fundamental mathematical sciences are taught not only in Malaysia but also in universities in Japan in their early semesters too, some of them thus feel difficulty in starting to study in Japan. This suggests that smooth study connection between Japan and Malaysia is not necessarily successful for them. The students who belong to MJHEP are said to be the smartest in Malaysia, it is thus likely that almost all the students in Malaysia who are going to study in Japan have the same inclination though the research was conducted only for MJHEP students who studied in Japan.

\section{Survey 1: Why Malaysian University Students Feel Difficulty in Studying Fundamental Mathematical Sciences}

In this section I conduct a brief survey from their answer sheets in MJHEP on why Malaysian university students felt difficulty in studying fundamental mathematical sciences. Investigating the cause would be useful for smooth study connection.

In MJHEP the subjects of fundamental mathematical sciences are taught according to textbooks generally used in universities in Japan. Students study all classes in Japanese. Figure 1 in Appendix shows representative answer sheets of mini test of calculus taught in MJHEP. As you can see from their answer sheets, they tend to lack some explanation in Japanese between formulas. Actually almost all the answer sheets lacked Japanese explanation in appropriate places. The reason why they were not good at explaining using Japanese may be that the abilities of science and technology Japanese had not been cultivated sufficiently. All of the students are enough good at fundamental Japanese to pass JLPT N4 (Japanese-Language Proficiency Test Level 4) in matriculation [6], while it is indicated that studying Japanese specialized for science and technology has different kinds of difficulty from studying fundamental Japanese.

As you can see from their answer sheets, they tend not to be able to finish slightly complex calculations or proofs. The reason why they were not good at complex calculations or proofs seems to the differences between the curriculums of mathematics in secondary education in Japan and Malaysia. Generally speaking, fundamental mathematical sciences taught in MJHEP and universities in Japan are based on mathematics taught in secondary education in Japan. Malaysian students in secondary education seldom solve proof questions and are allowed to use their calculators positively in their classes of mathematics. On the other hand, Japanese students in secondary education are encouraged to solve proof questions and they are fundamentally prohibited to use their calculators in their classes [7]. In addition, looking at general collection books of SPM questions, many numeric questions can be found, but proof questions can hardly be found [8] [9]. The differences of average scores between numeric and proof questions in 8 successive mini tests (max score is 2 each) were statistically significant in 7 out of 8 mini tests. The result is shown in Table 1 and suggests that their demonstrative abilities are inferior to their numeric abilities, which are both considered to be cultivated equally in education on mathematics in secondary education in Japan [10]. It is natural that there are differences between the curriculums in secondary education in two countries, but the differences of curriculums on mathematics between Japan and Malaysia can lead to obstacles of smooth study connection for Malaysian international students who study in universities in Japan.

To overcome such problems MJHEP provides the subjects of "Science and Technology Japanese" and "Basic Mathematics" for Malaysian university students.

\section{- Science and Technology Japanese:}

The subject of Japanese specialized for science and technology. Students read text written about science history, scientific discoveries, inventions and so on and they learn Japanese used in studying at departments of science and engineering in universities in Japan. 
Table 1. The differences of average scores between numeric and proof questions in 8 successive mini

tests

\begin{tabular}{|c|c|c|c|}
\hline Times & 1 & 2 & 3 \\
\hline Subjects & 105 & 101 & 95 \\
\hline $\begin{array}{c}\text { Ave. of } \\
\text { Numeric }\end{array}$ & 1.856 & 1.743 & 1.737 \\
\hline Ave. of Proof & 1.552 & 0.743 & 1.737 \\
\hline $\begin{array}{c}\text { P-Value } \\
\text { in T-test }\end{array}$ & $1.420 \mathrm{E}-05$ & $4.273 \mathrm{E}-25$ & 0.500 \\
\hline Statistically & Significant & Significant & Not Significant \\
\hline
\end{tabular}

\begin{tabular}{|c|c|c|c|}
\hline 4 & 5 & 6 & 7 \\
\hline 107 & 103 & 103 & 101 \\
\hline 1.907 & 1.951 & 1.874 & 1.871 \\
\hline 0.991 & 0.447 & 1.165 & 1.515 \\
\hline $1.159 \mathrm{E}-18$ & $1.993 \mathrm{E}-54$ & $1.056 \mathrm{E}-19$ & $6.172 \mathrm{E}-07$ \\
\hline Significant & Significant & Significant & Significant \\
\hline
\end{tabular}

\begin{tabular}{|c|}
\hline 8 \\
\hline 105 \\
\hline 1.886 \\
\hline 1.962 \\
\hline 0.040 \\
\hline Significant \\
\hline
\end{tabular}

- Basic Mathematics:

The subject of mathematics equivalent to mathematics taught in senior in high school in Japan. Students can make up for the basis of mathematics taught in universities because secondary education in Malaysia is one year shorter than that in Japan.

These subjects must be useful for Malaysian university students, but of course there exists time constraint in the course of MJHEP. It would be more instructive for them if they can study continuously "Science and Technology Japanese" and "Basic Mathematics" in universities in Japan. Do universities in Japan provide such classes as "Science and Technology Japanese" and "Basic Mathematics", which must be useful for overcoming the lack of abilities of science and technology Japanese and the differences in secondary education between Japan and Malaysia?

\section{Survey 2: How Universities in Japan provide Science and Technology Japanese and Basic Mathematics}

In this section a survey is conducted to count how many sections in universities in Japan provide the classes of "Science and Technology Japanese" and "Basic Mathematics". The larger the number of classes universities in Japan provide is, the more opportunities Malaysian university students in Japan have to overcome the problems. International centers and departments of science and engineering were selected according to the following scheme and the number of the centers and departments which provided such classes were counted.

Scheme: 22 universities in Japan, where MJHEP students were going to study in Japan.

The universities are listed in Table 3 in Appendix. Even if the names of the classes were different from "Science and Technology Japanese" or "Basic Mathematics", the contents of the classes were considered to be almost the same, then I regarded them as "Science and Technology Japanese" or "Basic Mathematics". The survey was based on the brochures, syllabuses and other related information the universities published by paper medium or on the web. The result is indicated in Table 2 .

Table 2. The number and percentage of providing classes of "Science and Technology Japanese" and

"Basic Mathematics" in universities in Japan

\begin{tabular}{|l|l|l|}
\hline & $\begin{array}{l}\text { Science and } \\
\text { Technology } \\
\text { Japanese }\end{array}$ & $\begin{array}{l}\text { Basic } \\
\text { Mathematics }\end{array}$ \\
\hline Providing & $\begin{array}{l}7 / 44 \\
(15.91 \%)\end{array}$ & $\begin{array}{l}5 / 44 \\
(11.36 \%)\end{array}$ \\
\hline $\begin{array}{l}\text { NOT } \\
\text { Providing } \\
\text { or unknown }\end{array}$ & $37 / 44$ & $39 / 44$ \\
$(84.09 \%)$ & $(88.64 \%)$ \\
\hline
\end{tabular}

In cooperative universities with MJHEP in Japan, there were only 7 classes of "Science and Technology Japanese" or equivalent and only 5 classes of "Basic Mathematics" or equivalent. This means few chances for Malaysian university students in Japan to study Japanese used in studying at departments of science and engineering and to prepare for fundamental mathematical sciences learned in universities in Japan. This may lead to their difficulties in starting to learn fundamental mathematical sciences, in other words, connecting their studies smoothly.

\section{Conclusion and Proposals}

In this paper I reported whether Malaysian international students who studied at universities in Japan were able to connect their studies smoothly, especially fundamental mathematical sciences. Here I want to offer proposals for their better studies in Japan.

First, as is shown in section 4, there are few chances for Malaysian university students to study science and technology Japanese and to prepare for fundamental mathematical sciences learned in universities in Japan. It would be instructive for them to study "Science and Technology Japanese" and "Basic Mathematics" at sections in universities in Japan. Recently the subject of "Basic Mathematics" or equivalent has been provided to Japanese students 
as "Remedial Mathematics" in many universities in Japan to review mathematics in secondary education [11]. Here I want to propose that universities in Japan provide opportunities for international students to study subjects' equivalent to "Remedial Mathematics" as "Basic Mathematics" specialized for international students. This may help them overcome the problems. And lecturers who can teach subjects of science and engineering should belong to international centers too in universities in Japan to provide the subject of "Basic Mathematics" for them though in many cases lecturers who can teach only subjects of humanities and social sciences belong to international centers in many universities in Japan.

Second, both universities and organizations in an international joint degree program should be careful of transferring credits of the subjects of fundamental mathematical sciences. Compared with specialized subjects, the subjects of fundamental mathematical sciences are based on secondary education of mathematics in each country, which is ordinarily different from each other. Thus there may be significant differences between the contents of the subjects of fundamental mathematical sciences taught in a university in country $\mathrm{A}$ and another university in country B. In international joint degree programs, admitting the transfer of the subjects of fundamental mathematical sciences with ease thus may lead to unexpected failure of international students in studying even if the names of the transferred subjects are the same. Both universities and organizations need to investigate the contents of the subjects thoroughly before admitting the transfer of the subjects.

Third, lecturers in both universities and organizations should have in common the contents of the transferred subjects of fundamental mathematical sciences and the scores of international students. The information must be useful for lectures who have the classes of fundamental mathematical sciences though such information is hardly appeared to lectures.

\section{Future Work}

For future work I want to conduct a survey on when international students feel difficulties in starting to study the subjects of science and engineering in universities in Japan and to propose efficient measures to help them study well.

\section{References}

[1] Zagaga, (2004). 'Joint Degrees - Problems and Developments', A presentation at the ERASMUS EUDORA meeting, Linz.

[2] Huang, F., (2006). 'Internationalization of University Curricula in Japan: Major Policies and Practice since the 1980s', Journal of Studies in International Education, pp. $102-118$.

[3] Michael, S. Balraj, L., (2003). 'Higher Education Institutional Collaborations: an analysis of models of joint degree programs' Journal of Higher Education Policy and Management, pp. $131-145$.

[4] Japan Student Services Organization, (2014). 'Result of an annual survey of international students in Japan 2014', pp. 4.

[5] JUCTe, (2014). Academic Monitoring Report MJHEP, Tokyo.

[6] The Japan Foundation and Japan Educational Exchanges and Services 'Japan-Language Proficiency Test’; http://www.jlpt.jp/index.html (6 December 2015).

[7] Okamoto, Y., (2007). 'For the expansion and the evolution of Research and Development of AV Equipment in Malaysia: Proposals for the improvement regarding the science and mathematics education', The Papers of Technical Meeting on History of Electrical Engineering, IEE Japan, pp. 3 - 9.

[8] Mun, C., (2015). Essential Complete Easy Examfocused SPM Mathematics, SASBADI SDN. BHD, Selangor.

[9] Huat, L. F., Cheng, Y. K., (2015). Essential Complete Easy Exam-focused SPM Additional Mathematics, SASBADI SDN. BHD, Selangor.

[10] Ministry of Education, Culture, Sports, Science and Technology 'The curriculum guideline in high school'; http://www.mext.go.jp/component/a_menu/education/micr o_detail/_icsFiles/afieldfile/2011/03/30/1304427_002.pdf (4 December 2015).

[11] Tsuji, Y., (2010). 'How we should design developmental education classes in a middle-ranking university?', Journal of Research Institute of St. Andrew's University, pp. $31-51$. 


\section{Appendix}
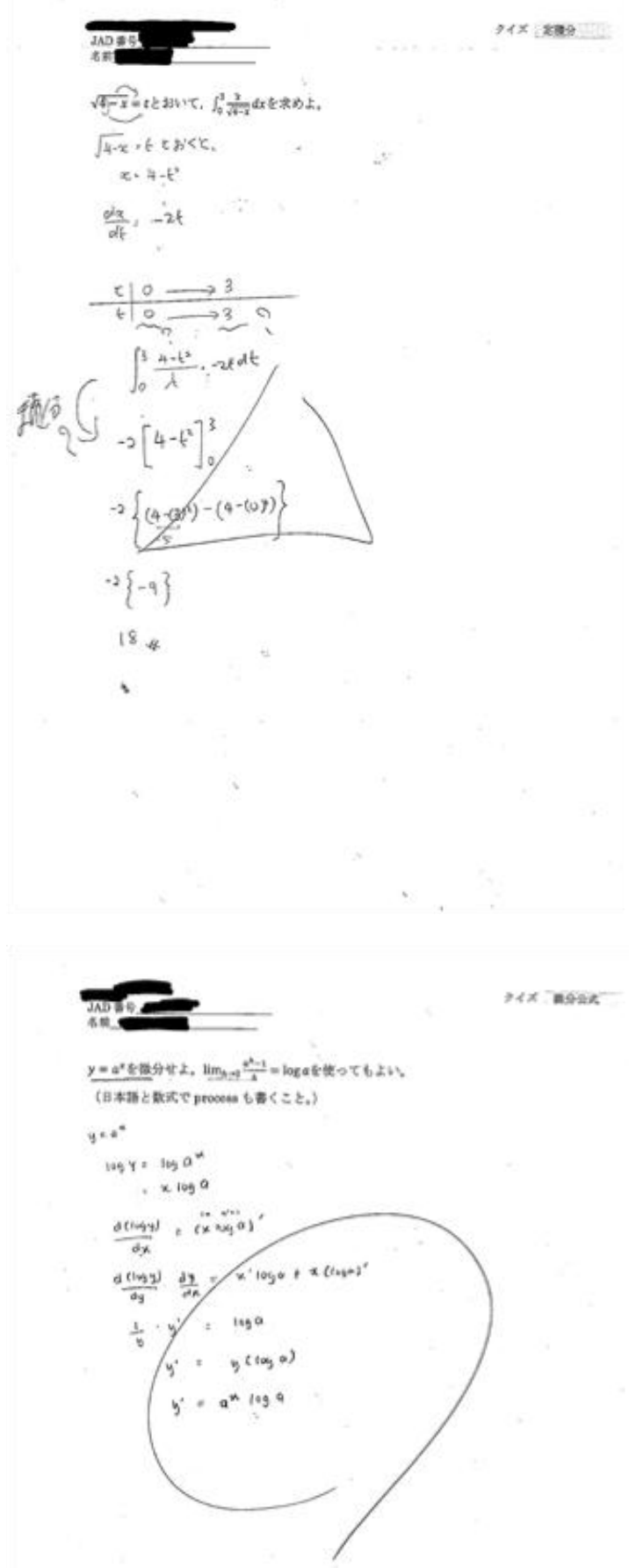

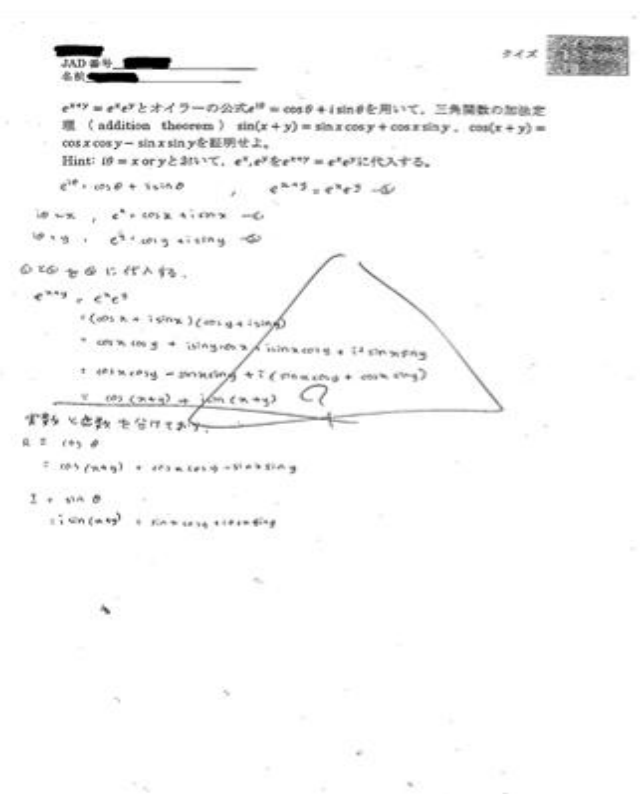

Figure 1. Representative answer sheets of mini tests of the subjects of fundamental mathematical sciences taught in MJHEP

Table 3. Cooperative universities in Japan with MJHEP

\begin{tabular}{|lr|ll|}
\hline $\begin{array}{l}\text { Okayama University of } \\
\text { Science }\end{array}$ & Ehime University & \\
\hline Kinki University & $\begin{array}{l}\text { Kyushu Institute of } \\
\text { Technology }\end{array}$ \\
\hline $\begin{array}{l}\text { Shibaura Institute of } \\
\text { Technology }\end{array}$ & Kumamoto University & \\
\hline Takushoku University & Saitama University & \\
\hline Tokai University & $\begin{array}{l}\text { Muroran Institute of } \\
\text { Technology }\end{array}$ & \\
\hline $\begin{array}{l}\text { Tokyo University of } \\
\text { Technology }\end{array}$ & Yamaguchi University & \\
\hline Tokyo Denki University & Sophia University & \\
\hline $\begin{array}{l}\text { Nagaoka University of } \\
\text { Technology }\end{array}$ & $\begin{array}{l}\text { Toyohashi University of } \\
\text { Technology }\end{array}$ \\
\hline $\begin{array}{l}\text { Tokyo University of } \\
\text { Science }\end{array}$ & $\begin{array}{l}\text { Nagoya Institute } \\
\text { Technology of }\end{array}$ \\
\hline Meiji University & University of Hyogo & \\
\hline Ritsumeikan University & University of Fukui & \\
\hline
\end{tabular}

